\title{
MIR222 Gene
}

National Cancer Institute

\section{Source}

National Cancer Institute. MIR222 Gene. NCI Thesaurus. Code C80726.

and acts as an oncogene in breast, lung, thyroid and prostate carcinomas as well as metastatic melanoma and glioblastoma multiforme. 